\title{
PROPOSTA DE VALOR EM EMPRESAS DO SETOR DE MODA: O ENTENDIMENTO DE GESTORES DE MARKETING E DE DESENVOLVIMENTO DE PRODUTOS
}

VALUE PROPOSITION IN COMPANIES OF THE FASHION SECTOR: THE UNDERSTANDING OF MARKETING AND PRODUCT DEVELOPMENT MANAGERS

\author{
EDSON ROBERTO SCHARF ${ }^{1}$ \\ MARCIO RODOLFO PAASCH ${ }^{2}$ \\ JAQUELINE DA SILVA ${ }^{3}$
}

RESUMO: Este estudo tem como objetivo identificar a proposta de valor de marcas de organizações de moda, no entender de decisores de áreas distintas. Foram envolvidos dois gestores de cada empresa pesquisada, especificamente executivos de Marketing e de Desenvolvimento de Produto. A técnica metodológica utilizada foi a de mapeamento cognitivo. A análise dos dados ocorreu pelas respostas comparadas dos grupos de respondentes, com o uso da Strategic Options and Development Analysis, conforme os preceitos de Eden (1988; 1989). Os resultados revelaram a existência de diferenças quanto a declaração da proposta de valor de cada grupo de gestores, ao mesmo tempo em que não se apresenta um alinhamento da proposição de valor entre os profissionais de uma mesma organização.

Palavras-chave: Proposta de valor. Branding. Moda. Mapas cognitivos. Marketing.

ABSTRACT: This study aims to identify the value proposition of the brand in the understanding of decision makers from distinct areas of fashion organizations. Two managers of each company surveyed, specifically Marketing and Product Development executives, were involved. The methodological technique used was that of cognitive mapping. Data analysis was performed by the comparative responses of the groups of respondents, such as Strategic Options and Development Analysis, according to Eden's $(1988,1989)$ precepts. The results revealed the existence of differences regarding the declaration of the value proposition of each group of managers, at the same time that there is no alignment of the value proposition among the professionals of the same organization.

Keywords: Value proposition. Branding. Fashion. Cognitive maps. Marketing.

Data de submissão: 18/04/2018. Data de aceite: 14/12/2018. Data de publicação: 17/12/2018.

\footnotetext{
${ }^{1}$ Docente e Pesquisador. PPGAD - Programa de Pós-Graduação em Administração. FURB - Universidade Regional de Blumenau. Endereço: Rua Antonio da Veiga, 140. CEP; 89030.903 - Blumenau - SC. E-mail: artigoes@gmail.com

2 Coordenador do curso de Administração. SENAI Educação.

${ }^{3}$ Mestranda no PPGDR. FURB - Universidade Regional de Blumenau
} 


\section{INTRODUÇÃO}

Poucas indústrias são tão dedicadas à construção de marcas quanto as de moda. 0 universo simbólico presente na área aponta para a necessidade de desenvolvimento de uma proposta de valor para a marca que permita o sucesso das organizações atuantes no segmento.

Diante disso, a identidade de marca surge como um diferencial estratégico para o setor de moda. Dentro das organizações nele inseridas, gestores e designers devem ter entendimento comum sobre essa identidade, para que as estratégias de ação de ambos os setores caminhem na mesma direção.

Identidade de marca é um fator crítico para essa indústria e, pela própria definição de moda, é afirmação que tem como base o fato de que seu produto é efêmero, conforme defendem Lipovetsky (2002) e Brandini (2007), modificando constantemente a sua oferta, embora a marca permanecendo imutável.

Como marcas do setor de moda necessitam de uma identidade claramente definida para não se esvaírem juntamente com sua natureza passageira, estratégias de criação de valor devem ser desenvolvidas por todos os indivíduos e organizações que, de alguma forma, podem influenciar a imagem da marca, a exemplo de gestores, estilistas, equipe de vendas ou fornecedores. Este envolvimento permite a construção de uma proposta de valor que sedimente a marca da empresa na mente dos consumidores e demais stakeholders.

No entanto, devido a interesses e atividades diversos, a proposição de valor pode ser entendida de maneira diferente por profissionais atuantes em uma mesma empresa. Este entendimento não alinhado pode minimizar o reconhecimento da marca, realçando problemas já existentes na empresa ou fazendo avançar novos. Dentre os principais motivos para entendimentos diferentes da proposta de valor em uma mesma empresa, segundo Jankovic (2012), estão comunicação inadequada, baixo nível de conhecimento dos produtos, interesses voltados a um único ou poucos setores da empresa, falta de visão no longo prazo ou perda do senso de realidade do mercado.

Este entendimento diverso, quando profissionais de uma mesma organização aplicam no seu trabalho conceitos diferentes para o mesmo esforço, pode limitar ou mesmo eliminar o efeito das iniciativas mercadológicas realizadas pelas organizações.

Realizar estudos com o fito de compreender o pensamento de profissionais decisores em empresas competitivas sobre a proposição de valor, se mostra iniciativa importante como apoio ao aperfeiçoamento do conhecimento acadêmico sobre a temática, e relevante do ponto de vista executivo.

Assim, este trabalho tem o objetivo de identificar a proposta de valor de marcas de organizações de moda, no entender de decisores de áreas distintas e, mais especificamente, a declaração de como esta proposta de valor de marca é apresentada por diferentes decisores das empresas estudadas.

\section{FUNDAMENTAÇÃO TEÓRICA}

A seguir, os principais conceitos que embasam o estudo.

\subsection{Identidade de marca}

Marca é uma comunicação de valor e um mecanismo de distinção de bens ou serviços. Por meio dela, o consumidor pode interpretar e decidir suas escolhas de compra. Para Kapferer (2012), é a soma intangível dos atributos relacionados a um produto, como nome, 
preço ou reputação. Para o autor, uma marca é definida pelas impressões dos consumidores sobre as pessoas que a usam e pela sua própria experiência pessoal.

Empresas que não possuem marcas reconhecidas no mercado geralmente só se diferenciam pelas características técnicas do produto ou pelo preço, ambas situações facilmente copiáveis por concorrentes. É preciso, portanto, dar uma identidade à marca ou ao portfólio de marcas da organização. Identidade de marca, segundo Aaker e Joachimsthaler (2000), compreende o conjunto de atributos intangíveis e tangíveis da marca e o significado que a organização deseja comunicar aos consumidores-alvo. Karjalainen (2007) aponta que empresas enfatizam as atividades de construção da identidade de marca para obter consciência, promover seu reconhecimento e apresentar ofertas distintas.

O desenvolvimento da identidade de marca é fundamental para a diferenciação de bens e serviços em mercados competitivos, espaço onde o consumidor pode escolher dentre um conjunto amplo de produtos, conforme entende Jankovic (2012). Ao construir uma identidade, a marca comunica seus atributos, criando significado perante a sociedade. Aaker (2007) enfatiza que para atingir os objetivos da identidade de marca, o posicionamento tem de estar adequadamente projetado, com a organização criando diferenciais.

Estudo bibliométrico pioneiro no Brasil sobre o tema de Identidade de Marca apresentou o estágio em que se encontra a literatura acadêmica nacional na área. Os autores Scharf, Vieira e Krause (2013) concluíram ser compreensível que, em sua maior parte, os artigos tenham teor conceitual, ensejando um encontro de linguagens e experiências de uma temática que se encontra ainda em fase de crescimento na discussão acadêmica. Para tratar de identidade, segundo os autores, é aconselhável discutir o significado de marca, nos seus diversos entendimentos.

Autores diversos desenvolveram modelos de construção de identidade de marca. Davis (2000) tem no modelo BAM - Gestão do Ativo da Marca (Brand Asset Management, no original em inglês) a oportunidade de expor a marca como a variável mais importante de todas as possíveis na organização; Kapferer (2003) desenvolveu o Prisma de Identidade da Marca, que permite analisar a marca para discernir suas forças e fraquezas; dentre os elementos principais do modelo de Nunes (2003), denominado de Modelo Alternativo MercadoEstratégia-Estrutura (alternativo, pois foi baseado no modelo Strategy and Structure, de Alfred Chandler, de 1962), está a ênfase da proposta de valor nos aspectos monetários da marca, com o uso de indicadores da marca no mercado, da marca na empresa e de resultados da marca na empresa; García (2005) desenvolveu o Modelo de Construção de Marcas, abordando quatro etapas: o desenvolvimento da identidade da marca (onde está situado um elemento de proposta de valor), o posicionamento da marca, a elaboração da identidade formal e o desenvolvimento da estratégia de administração de ativos da marca; Keller e Machado (2006), em seu modelo Estratégia de Marca Baseada no Consumidor, explora o nível de conhecimento e consciência da marca pelo consumidor e de como este avalia a imagem da marca. Ghodeswar (2008) propôs o modelo PCDL, em que defende que o esforço de construção da marca deve estar alinhado com os processos organizacionais que auxiliam a entregar as promessas aos clientes em todos os departamentos, intermediários, fornecedores e outros stakeholders. A nomeclatura PCDL veio da inicial dos quatro elementos componentes do modelo (em inglês, no original: positioning the brand, communicating the brand message, delivering the brand performance e leveraging the brand equity). Mindrut, Manolica e Roman (2015), embora não tenham apresentado um modelo próprio, se utilizaram daquele defendido por Keller e Machado em 2006, para estudar componentes de uma identidade de marca e obter uma hierarquia da importância dos elementos e sua dimensão de impacto. 
O estudo ora desenvolvido leva em consideração as variáveis propostas por David Aaker (2007), no modelo denominado Aaker Model - Planejamento de Identidade da Marca, com sua construção baseada em três grandes áreas: Análise Estratégica, Sistema de Identidade de Marca (onde está situada a proposta de valor) e Sistema de Implementação da Identidade da Marca. Foi acrescida à área Sistema de Identidade de Marca a proposição de Scharf (2009; 2012), com a proposta de valor doravante se concentrando em quatro benefícios: funcional, emocional, de autoexpressão e do capital humano.

A comunicação que ocorre na área da moda se beneficia de uma identidade forte, mas é cada vez mais complexo o processo de acerto, dada a volatilidade dos interesses dos indivíduos. Quanto a isto, Hall (2006) defende que a identidade múltipla característica do indivíduo contemporâneo vem de uma série de mudanças estruturais na sociedade, principalmente a globalização e sua obrigatória conexão entre culturas distantes. Esta sociedade de mudanças rápidas tem como principal motivador a novidade.

Weblogs de moda são canais cada vez mais influentes junto aos consumidores, com as marcas os utilizando como espaços midiáticos, por meio de investimento em apresentadoras como porta-vozes de um novo formato de comunicação de moda. Representantes de épocas e conceitos distintos, as marcas Chanel e Dior, por exemplo, podem conviver no mesmo estilo de aparência, refletindo uma identidade contemporânea, múltipla, contraditória e transitória das usuárias.

O reflexo dessa identidade contemporânea pode se transformar na proposta de valor da marca anunciante.

\subsubsection{Proposta de valor}

O valor da marca é a declaração, por parte da empresa, do seu significado ao consumidor. A mensagem de valor declarada se baseia no significado que o consumidor atribui a ela, segundo Kapferer (2012). O reconhecimento reflete a familiaridade decorrente de exposição anterior e, segundo Scharf (2012), não envolve a lembrança de onde a marca foi vista antes ou a classe de produtos da marca.

Ela favorece o correto posicionamento da marca que, no entender de Upshaw (1999), se refere ao pertencimento da diferença, ou seja, como o consumidor posiciona uma marca em relação a outra em sua mente. Para o autor, o posicionamento de marca contém quatro elementos: a promoção de uma vantagem competitiva, o atingimento de um target definido, a comunicação ativa e uma proposta de valor. Aaker (2007) afirma que posicionamento é a parte da identidade de marca e da proposta de valor ativamente comunicada ao target e que demonstra vantagens sobre as marcas concorrentes. Frow, McColl-Kennedy, Hilton, Davidson e Payne (2014) argumentam, porém, que apesar do interesse significativo no conceito de proposta de valor, há concordância limitada sobre sua natureza e seu papel organizacional. Complementam afirmando que há pouca compreensão de sua aplicação em um mundo cada vez mais em rede.

Treacy e Wiersema (1996) defendem que proposta de valor é a declaração sobre o que o consumidor terá como experiência após saber da promessa de mercado realizada pela empresa. Aaker e Joachimsthaler (2000), afirmam que é utilizada como uma ferramenta por meio da qual os benefícios oferecidos pela marca ao cliente são evidenciados, aumentando o seu valor. Bititci et al. (2004), afirmam que a aplicação desse conceito modifica as operações empresariais internas e externas, redefinindo competências e capacidades. Tuominen (2004), declara que uma proposta de valor testada é essencial para um negócio de sucesso. Como a proposta de valor pode melhorar a eficiência e eficácia do processo interno de um 
determinado bem ou serviço, a empresa teria mais clientes retidos e redução de custos, o que leva a acionistas satisfeitos, aumento de lucro e aumento de participação de mercado. Knox (2004), argumenta que proposta de valor é uma declaração escrita enfocando todos as atividades de mercado da organização em elementos críticos do cliente. Ela cria um diferencial significativo no processo de decisão do cliente, para que ele opte pela oferta da organização propositora ao invés da concorrente.

Kowalkowski (2011), porém, argumenta que a habilidade organizacional em comunicar propostas de valor de forma estratégica e eficaz ainda é uma área em desenvolvimento como centro de vantagem competitiva. A proposição de valor é a ideia central que guia a organização sendo, segundo Varadarajan (2011), a promessa de entrega de uma combinação única de valores aos consumidores. Frow e Payne (2011), por sua vez, defendem que a proposta de valor tem papel central na cocriação de valor entre os stakeholders. Para os autores, o desenvolvimento de uma proposição de valor em domínios múltiplos de stakeholders pode fornecer mecanismos importantes para alinhar valor dentro de um sistema de Marketing. Ainda assim, Kohtamäki e Partanen (2016) advogam que relacionamentos fornecedor-cliente, dentro ou fora da organização, não geram desempenho em si, pois devem, antes, serem caracterizados pelo aprendizado na cocriação de valor.

Se levado em consideração o entendimento de Kapferer (2012), para quem a sociedade de consumo desenvolvida tem como premissa atender aos desejos, fantasias, paixões e exigências por meio de signos, códigos e símbolos, então se pode deduzir que é a marca, com sua proposta de valor, o elemento que agrupa tudo em um só espaço.

A proposição de valor dos vários envolvidos, os stakeholders, fornece oportunidades aprimoradas para a criação de valor e pode ajudar os gerentes a alinhar valor e estabilizar relacionamentos dentro de uma rede de valor organizacional, segundo Frow e Payne (2011). A moda, como setor e como produto de consumo, se apoia em uma proposta de valor que a suporte ante a concorrência e a dita efemeridade da sua ideia.

\subsection{Moda}

A moda é caracterizada pela sua volatilidade, baixa previsibilidade, ciclo de vida curto dos produtos e elevado volume de compra por impulso. Christopher, Lowson e Peck (2004), sugerem que a velocidade e as mudanças rápidas se tornam sinônimos de mercados de moda, criando necessidade de flexibilidade e capacidade de resposta rápida para manter a empresa sustentável em um mercado competitivo. Para Alverez, Favero e Francisco (2013), a moda é mudança e está alinhada com ciclos de curto prazo, entendidos como tendências.

Lipovetsky (2002), admite que moda e identidade de marca "...estão bem amarrados..." (p. 171). O autor complementa dizendo que "jamais se consome um objeto por ele mesmo ou pelo valor de uso, mas em razão de seu valor de troca". O autor continua, à mesma página, afirmando que isto decorre do prestígio e da posição social que confere. Por sua vez, Mandhachitara e Piamphongsant (2016), afirmam que moda, com sua natureza efêmera, direcionada para um comportamento aprovado pelos membros pertencentes a grupos sociais, simboliza um ponto forte na sociedade contemporânea, que busca por reconhecimento e status.

Moda, no entendimento de autores como O'Hara (1993) e So, Parsons e Yap (2013), é a imagem do que o indivíduo é no tempo em que ele vive, já que a roupa sempre foi utilizada como instrumento para exibir riqueza e posição social. A moda, portanto, se aproxima de símbolos e pode ser interpretada como discurso. Com a mesma percepção, Souza (1996) entende que moda é uma linguagem da estrutura social que apresenta ideias e sentimentos. 
Neste sentido, McCracken (2012) afirma que o consumo é plenamente cultural, envolvendo significados socialmente aceitos. Para o autor, é por meio do significado cultural daquilo que é consumido que é apresentado ao mundo o sistema de relações e representações sociais de cada indivíduo.

A indústria da moda tem como característica a concorrência, exigindo das organizações o desenvolvimento de estratégias para diferenciação. Estas têm o objetivo, segundo autores como Lewis e Hawksley (1990) e Birtwistle e Freathy (1998), de desenvolver a vantagem competitiva e explorar novos setores, mantendo seus produtos atraentes aos consumidores.

Outra característica das marcas de moda é a forte ligação entre as atividades de design e de Marketing. A conexão e a interdependência delas varia de acordo com o tipo de marca e o segmento de atuação, segundo Martin, Veer e Pervan (2007). Para os autores, marcas mais luxuosas dão mais poder ao designer; marcas que carecem do esforço de branding geram mais poder ao esforço de Marketing.

Brïdson e Evans (2004), defendem que os símbolos de status que são próprios da moda são geradores de representações sociais que comunicam aos indivíduos a que grupo social pertencem. Desta maneira, a moda é um indicativo importante para a aceitação ou o distanciamento entre grupos ou classes sociais, segundo So et al. (2013).

Apesar da evidente complexidade e de diversos stakeholders envolvidos no processo de criação de moda, Rech (2006, p. 72) defende que "no atual contexto, o valor de uma marca famosa e/ou confiável é mais prestigioso ao produto do que as ações produtivas".

\section{METODOLOGIA}

Este trabalho se caracteriza como uma pesquisa de caráter exploratório que, para Vergara (2000), tem como objetivo alcançar compreensão de razões e motivações. Quanto à abordagem do problema é qualitativa, considerando haver uma relação dinâmica entre o mundo real e o sujeito, ou seja, "há um vínculo indissociável entre o mundo objetivo e a subjetividade do sujeito que não pode ser traduzido em números", conforme dito por Silva e Menezes (2005, p. 20).

Para cumprir o objetivo de analisar a proposta de valor da marca, expressa por decisores de áreas distintas de organizações detentoras de marca de moda, foi utilizada a técnica de mapeamento cognitivo das suas declarações. O mapeamento cognitivo tem origem no estudo de problemas relacionados com decisões e políticas organizacionais, conforme Eden (1988; 1989). O autor informa que é uma abordagem fundamentada em explorar a experiência dos indivíduos envolvidos em alguma situação dentro da organização. Cada indivíduo possui uma estrutura própria de postulados que formam um sistema de constructos, ou seja, um conjunto finito de conceitos interligados utilizado para explicar o contexto e as consequências das suas ações como indivíduo. O autor (1988) defende que este sistema de constructos é particular de cada pessoa, uma vez que esta percebe aspectos diversos das situações, articulando de maneira diferente estas percepções como meio de explicar as ações e as tomadas de decisão.

A coleta dos dados foi realizada por meio de entrevistas, com cumprimento dos seguintes procedimentos: formulação do convite via e-mail ou na forma presencial; agendamento da entrevista; aplicação de uma prévia conversa para obtenção do perfil do entrevistado, seguida de explicação sobre natureza e objetivos da pesquisa; apresentação dos vinte e sete elementos da proposta de valor constantes do estudo de Scharf (2009); apontamento dos elementos constantes da proposta de valor; e consecução da entrevista. 
Como dito por Jankovic (2012), há motivações para que ocorram entendimentos diversos sobre a proposta de valor desenvolvida pela alta gerência, tendo como possível resultado a comunicação indevida ao mercado, seja por meio dos produtos ofertados ou da propaganda veiculada. Neste sentido, se buscou entrevistar executivos de empresas cujas marcas estão consolidadas junto aos consumidores, e cujas respostas possam ser a reverberação daquilo que o segmento fabril pensa. Os pesquisadores relacionaram organizações da área de moda, sediadas em Santa Catarina, estado reconhecido como polo têxtil referencial no país. Esta relação inicial se deu por pesquisa no sítio eletrônico da Santa Catarina Moda \& Cultura (SCMC), entidade que nasceu e é mantida por empresários de moda de portes diversos, e que reflete os interesses maiores do setor. Foram encontradas trinta e sete empresas. Após, foi solicitado a um consultor de moda que apontasse as marcas mais consolidadas no meio, a partir desta lista inicial. Foram indicadas nove organizações. Em seguida, os pesquisadores buscaram triangular essa relação de empresas selecionadas pelo profissional com empresas catalogadas em relatório setorial trianual da Federação das Indústrias do Estado de Santa Catarina (2015), em que estão presentes as maiores empresas do ramo. Estas empresas, normalmente, refletem a excelência em sua área de atuação. Foram encontradas cinco organizações. Ao serem contatadas e convidadas a participar do projeto, quatro aceitaram prontamente e uma se negou argumentando estar momentaneamente sem um profissional de Marketing. Evidentemente, isto inviabilizaria a entrevista dupla. Assim, foram entrevistados gestores de quatro empresas de Santa Catarina que possuem marca de moda própria, citadas como referência na área têxtil e do vestuário no estado catarinense.

De cada empresa, foram entrevistados um executivo de Marketing e um de Desenvolvimento de Produto com poder de decisão em seu setor e que influenciam, de forma direta, o delineamento de estratégias para a construção da proposta de valor das marcas de suas respectivas organizações. Estes profissionais estão conectados muito proximamente às atividades relacionadas à marca e aos produtos, mais do que qualquer outro profissional em uma empresa de moda. Os respondentes participantes foram apontados pelas empresas como sendo colaboradores com autonomia para tomar decisões em suas áreas, cabendo a estes a responsabilidade de aplicar o seu entendimento sobre a proposta de valor nas decisões das marcas estudadas. No total, portanto, foram quatro organizações e oito respondentes, sendo quatro profissionais da área de Marketing e quatro da área de Desenvolvimento de Produto.

Ao final do procedimento de entrevistas, as respostas foram comparadas por meio da construção de mapas cognitivos de grupo usando a técnica metodológica doravante denominada de SODA, do original em inglês Strategic Options and Development Analysis, conforme os preceitos de Eden (1988; 1989), com uso dos elementos de proposta de valor constantes nos estudos de Scharf $(2009 ; 2012)$.

A técnica Soda auxilia o tomador de decisão a lidar com problemas complexos por meio de uma modelagem qualitativa que permita explorar diferentes visões sobre um problema. Seus resultados ajudam a determinar pontos importantes, guiar discussões e obter comprometimento das pessoas envolvidas em torno das ações recomendadas. É, portanto, um procedimento fortemente aderente ao ambiente corporativo. Bastos (2002) aponta que mapas cognitivos têm sido utilizados em diversos domínios organizacionais nos quais se busca identificar estruturas de conhecimento que guiam a percepção, o julgamento e as decisões, tanto no nível dos indivíduos (sobretudo executivos e gestores), quanto no de grupo, da organização e de grupos de organizações. Estudos como o de Barreto (2015), que buscam compreender de que maneira os profissionais da área de Marketing de Relacionamento 
entendem a formação dos resultados principais dessa atividade, pelo uso dos mapas cognitivos, reforçam o uso desse método em pesquisas científicas.

Portanto, cada gestor apontou os elementos da proposta de valor que julgava importantes para sua organização. Na sequência, foi apresentada uma matriz em que o respondente atribuiu, para estes elementos escolhidos, um peso de influência sobre outro elemento também apontado por este decisor (notas de -3 para influência negativa forte, -2 para média, -1 para fraca, 0 para não apresenta influência, +1 para influência positiva fraca, +2 para média e +3 para os elementos que apresentam influência positiva forte). Em todo o processo, o decisor estava ciente de que deveria apresentar sua opinião, e esta não seria julgada, nem seu nome e organização revelados. Durante a entrevista, houve apenas anotações da nota na matriz, sem gravações de voz, visto que o objetivo com a utilização deste método é a identificação do entendimento do gestor sem a pressão pela resposta, seguindo recomendação de Barreto (2015).

\section{ANÁLISE DOS DADOS}

Após a coleta dos oito mapas cognitivos individuais, foram analisadas as diferenças entre eles e, com base nessa análise, identificadas as similaridades e as divergências presentes nas declarações.

O quadro 1, que apresenta uma visão geral dos elementos apontados pelos oito gestores, dentre os vinte e sete apresentados inicialmente por Scharf (2009; 2012), dá destaque aos elementos da proposta de valor que receberam mais menções. Foram somados os apontes de cada gestor por empresa e somados. Em seguida, se destacou os elementos comuns entre os gestores por empresa.

Quadro 1 - Proposta de valor apontado pelos gestores

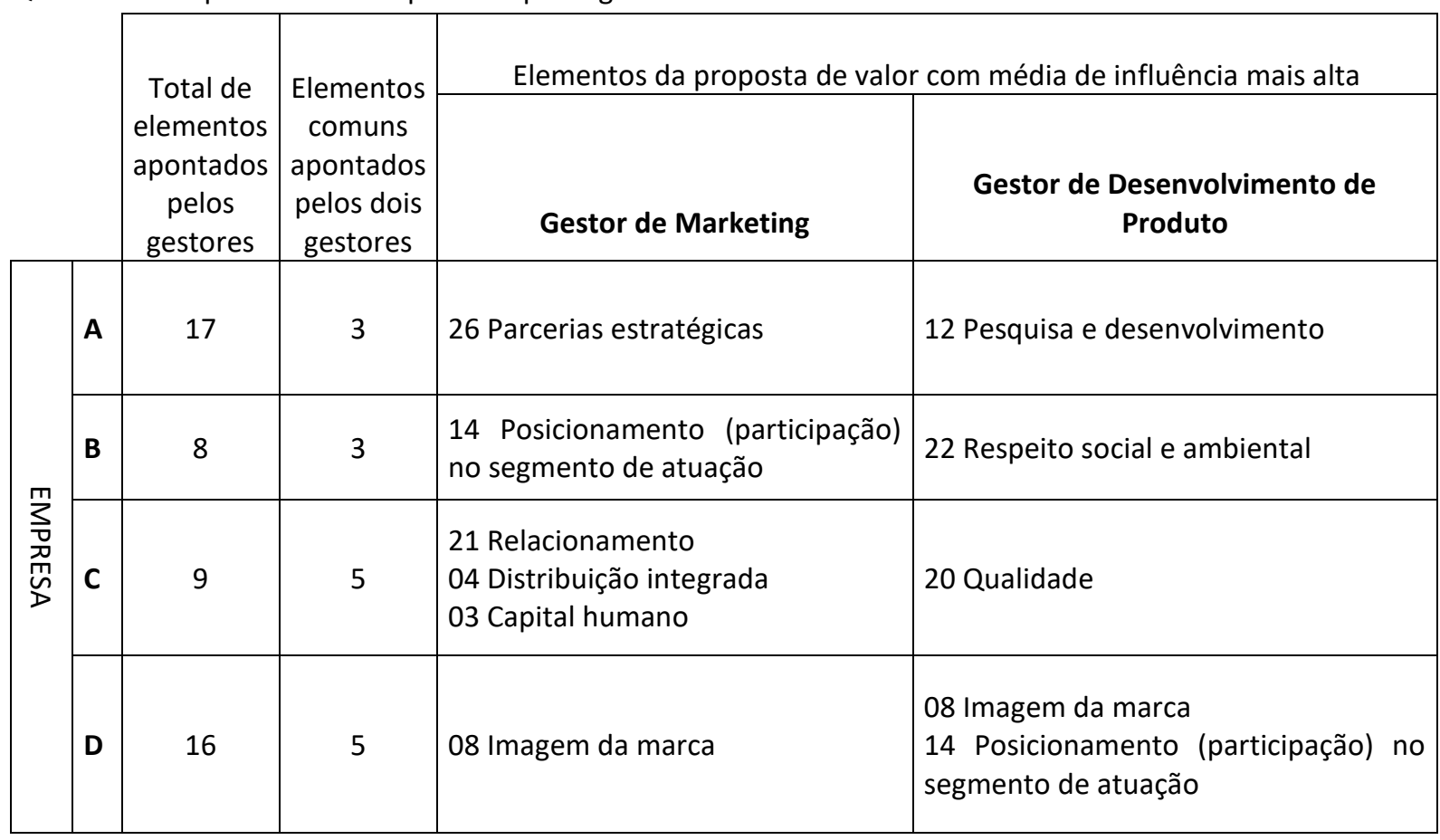

Fonte: Elaborada pelos autores (2018).

Apesar de as quatro empresas terem propostas de valor diferentes, o que impede o comparativo direto, fica evidenciado o baixo nível de entendimento dos gestores de uma 
mesma empresa em relação à proposta de valor. Somente uma dupla de profissionais apresentou um elemento idêntico (Imagem da marca), sendo que um dos dois ainda somou a este, outro elemento (Posicionamento). Tanto do ponto de vista da lacuna dos executivos de Marketing em relação aos de Desenvolvimento de Produto quanto do ponto de vista linear por empresa, quase inexiste conexão entre um e outro entendimento. É esperado que profissionais de uma mesma organização possam ter a leitura da proposição de valor senão idêntica, ao menos semelhante, posto que ela é única para toda a empresa. Isto não transpareceu nesse levantamento.

\subsection{Mapa agregado por decisor}

Para compreender a diferença entre gestores de Marketing e gestores de Desenvolvimento de Produto, importa observar a análise das matrizes seguinte (tabela 1). Nesta etapa, elas possuem linhas representando os nós de origem (causa), e colunas representando os nós de destino (efeito) da relação causal.

$O$ conteúdo dessa célula é um par ordenado $(k ; l)=(8 ; 2.75)$ onde $k$ representa o número de vezes em que a relação causal apareceu na pesquisa e / representa a média dos impactos que foram julgados existir nessa relação. Para Crescitelli e Figueiredo (2010), é dessa forma que se pode julgar a força de cada relação causal, com a ponderação do número de votos que a relação teve e o impacto médio desta relação.

A matriz dos gestores de Marketing pode ser observada na tabela 1, em que se tem conexões, número de votos da relação e impacto médio da relação.

Tabela 1 - Matriz agregada dos gestores de Marketing (refinada)

\begin{tabular}{|c|c|c|c|c|c|c|c|c|c|c|}
\hline & 4 & 8 & 12 & 14 & 15 & 17 & 18 & 20 & 21 & 22 \\
\hline 4 & & $(2 ; 2.5)$ & & $(3 ; 3)$ & $(2 ; 1.5)$ & $(2 ; 0.5)$ & $(2 ; 1.5)$ & $(2 ; 2)$ & $(3 ; 2.66)$ & $(2 ; 1)$ \\
\hline 8 & $(2 ; 2.5)$ & & & $(2 ; 2.5)$ & & $(2 ; 1)$ & & $(2 ; 1.5)$ & & \\
\hline 12 & $(2 ; 1)$ & & & & & & & & & \\
\hline 13 & & & & & & & & & & \\
\hline 14 & $(3 ; 2.33)$ & $(2 ; 2.5)$ & $(2 ; 2)$ & & & $(2 ; 1)$ & & $(2 ; 1.5)$ & $(2 ; 2)$ & \\
\hline 15 & $(2 ; 1)$ & & & & & & & $(2 ; 1)$ & $(2 ; 1)$ & \\
\hline 17 & $(2 ; 2.5)$ & & & $(2 ; 2.5)$ & & & & $(2 ; 1)$ & & \\
\hline 18 & $(2 ; 1)$ & & & & & & & $(2 ; 3)$ & & \\
\hline 20 & $(3 ; 1.66)$ & $(2 ; 2.5)$ & & $(2 ; 2.5)$ & $(2 ; 0.5)$ & & $(2 ; 3)$ & & $(2 ; 1)$ & \\
\hline 21 & $(3 ; 2)$ & & & $(2 ; 2)$ & $(2 ; 1)$ & & & $(2 ; 2)$ & & $(2 ; 1)$ \\
\hline 22 & $(2 ; 1)$ & & & & & & & & $(2 ; 2)$ & \\
\hline
\end{tabular}

Fonte: Elaborada pelos autores (2018).

A figura 1 corresponde ao mapa agregado dos gestores de Marketing, apresentado na tabela 1, com destaque para os elementos com fundo claro, que são os mesmos apontados pelos gestores de Desenvolvimento de Produto. 
Figura 1 - Mapa agregado dos gestores de Marketing

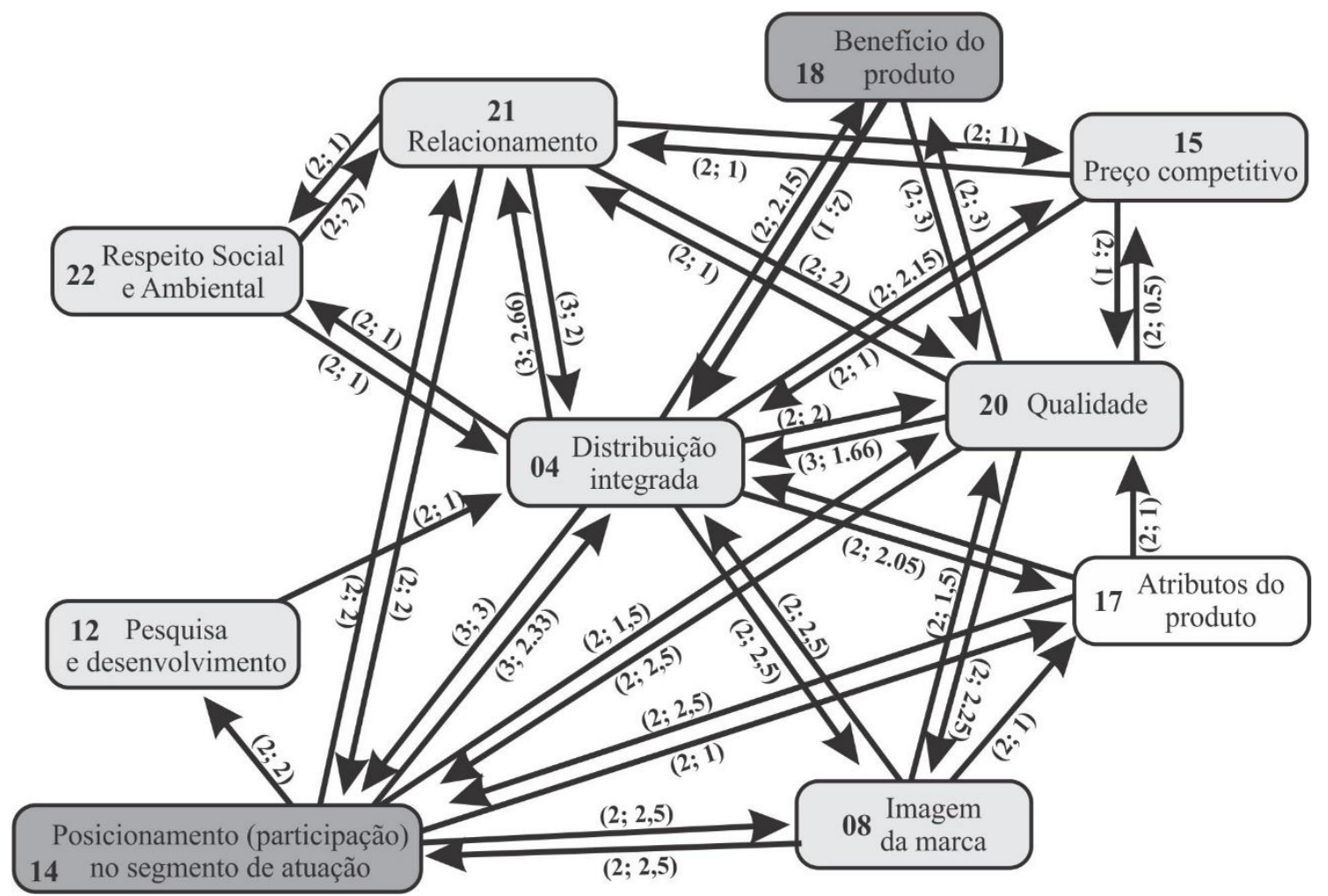

Fonte: Elaborada pelos autores (2018).

Observando o que foi apontado pelos gestores de Marketing, em quantidade de causa e efeito, fica evidenciado que o seu entendimento dos elementos da proposta de valor de marca está alinhado com o processo de gestão, à exceção do elemento 20 (qualidade), que é inerente ao produto. Os elementos apontados em ordem de importância pela quantidade qualificada de conexões (média da nota de influência conforme gradação de $-3 a+3$, explicada no capítulo 3) são os de número 4 (distribuição integrada) com 17 arcos, 21 (relacionamento) com 10 arcos, 20 (qualidade) com 13 arcos e o elemento 14 (posicionamento) com 14 arcos.

$\mathrm{Na}$ tabela 2, como já desenvolvido na matriz anterior, segue o refinamento da matriz agregada dos gestores responsáveis pela decisão do produto com, no mínimo, duas citações do elemento e média diferente de zero.

Tabela 2 - Matriz agregada dos gestores de Desenvolvimento de Produto (refinada)

\begin{tabular}{c|c|c|c|c|c|c|c|c|c} 
& $\mathbf{3}$ & $\mathbf{4}$ & $\mathbf{7}$ & $\mathbf{8}$ & $\mathbf{1 2}$ & $\mathbf{1 5}$ & $\mathbf{2 0}$ & $\mathbf{2 1}$ & $\mathbf{2 4}$ \\
\hline $\mathbf{3}$ & & $(2 ; 0.25)$ & $(2 ; 1)$ & $(2 ; 1.5)$ & & & & & \\
\hline $\mathbf{7}$ & $(\mathbf{2} ; \mathbf{3})$ & $(2 ; 2.5)$ & & $(2 ; 1.5)$ & $(2 ; 1)$ & & & & \\
\hline $\mathbf{8}$ & $(2 ; 1.5)$ & $(2 ; 3)$ & $(2 ; 2)$ & & $(2 ; 2.5)$ & & & $(2 ; 2)$ & $(2 ; 2.5)$ \\
\hline $\mathbf{1 2}$ & & $(2 ; 2.5)$ & $(2 ; 2.5)$ & $(2 ; 2)$ & & & & & \\
\hline $\mathbf{1 5}$ & & $(2 ; 1)$ & & $(2 ; 2.5)$ & & & $(2 ; 0.5)$ & & \\
\hline $\mathbf{2 2}$ & & & & & & $(2 ; 1)$ & $(2 ; 1.5)$ & & \\
\hline $\mathbf{2 4}$ & & & & $(\mathbf{2} ; \mathbf{3})$ & & & & $(2 ; 2.5)$ & \\
\hline
\end{tabular}

Fonte: Elaborada pelos autores (2018). 
Destaque para a forte influência (média 3) do elemento 7 (gestão do conhecimento) sobre o elemento 3 (capital humano), do elemento 8 (imagem da marca) sobre o elemento 4 (distribuição integrada) e do elemento 24 (tradição) sobre o elemento 8 (imagem da marca).

Figura 2 - Mapa agregado dos gestores de Desenvolvimento de Produto

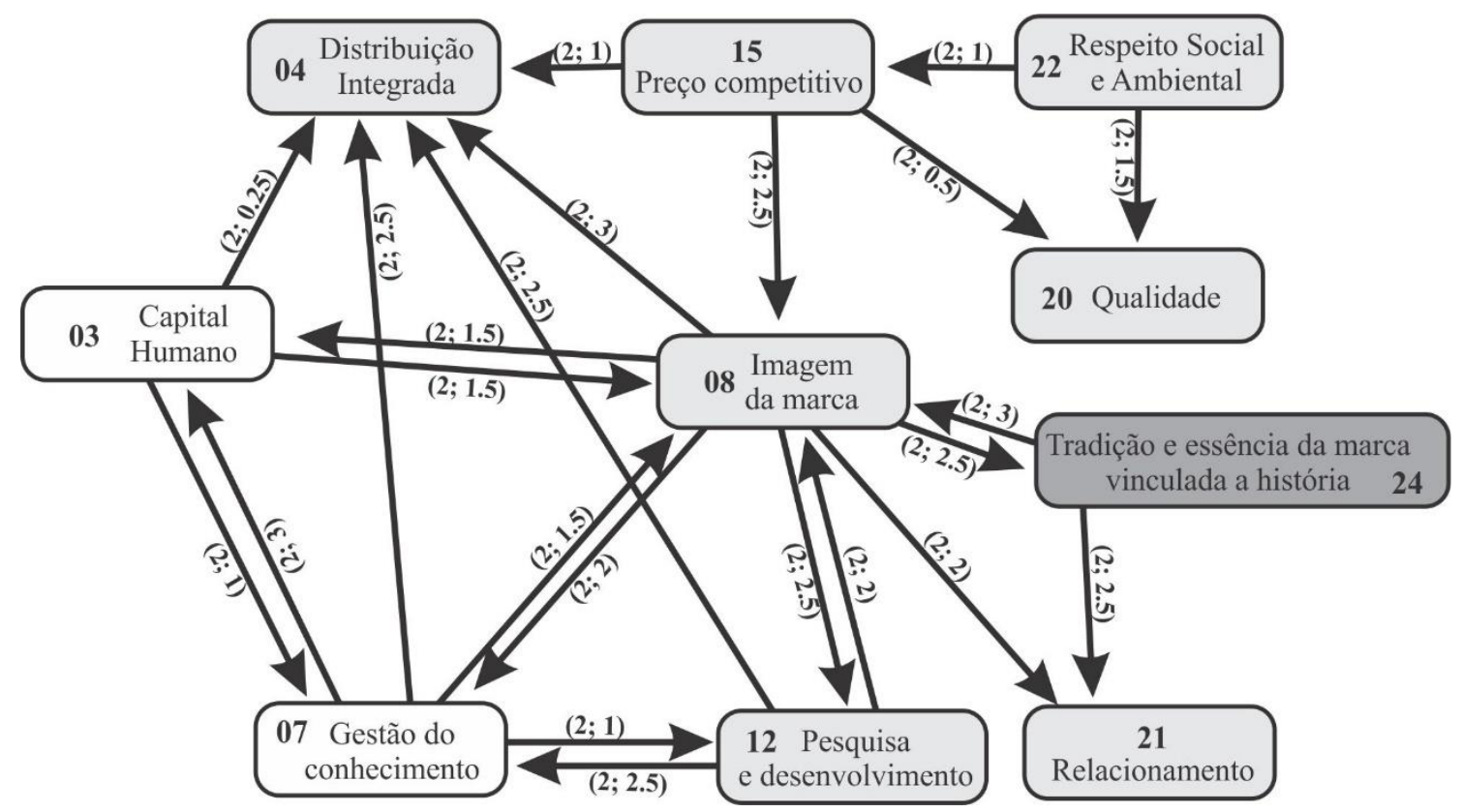

Fonte: Elaborada pelos autores (2018).

A figura 2 corresponde ao mapa agregado dos gestores de Desenvolvimento de Produto, apresentado na tabela 2. A matriz agregada revela que para esses profissionais o elemento que possui maior quantidade de arcos de causa e efeito é o de número 8 (imagem da marca) com oito arcos, seguido pelo 7 (gestão do conhecimento) com sete arcos. Foi verificado que os gestores de Desenvolvimento de Produto apontaram os elementos 3 (capital humano) e 7 (gestão do conhecimento), não mencionados pelos gestores de Marketing, o que mostra a maior preocupação com o capital humano envolvido com a marca. O elemento 17 (atributo do produto) não foi citado pelos gestores de Desenvolvimento de Produto, sendo apontado somente pelos gestores de Marketing, com seis arcos de causa e efeito.

De maneira a facilitar a compreensão da diferença entre os dois perfis de gestores e as distâncias entre seus mapas cognitivos, a seguir é apresentado recorte dos sete elementos citados em ambos os mapas cognitivos agregados por grupo de gestores. São demonstrados nas figuras de 3 a 9.

Figura 3 - Diferença do elemento 4 - gestores de Desenvolvimento de Produto e gestores de Marketing

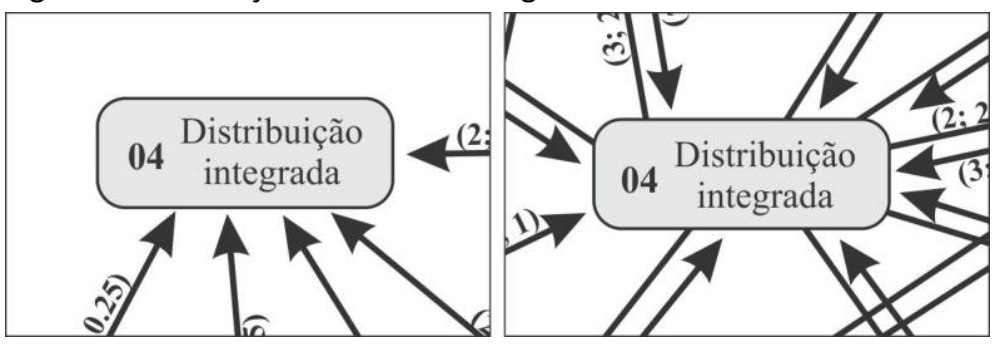

Fonte: Elaborada pelos autores (2018). 
Ao analisar o elemento 4 (distribuição integrada), apontado por ambos os grupos de gestores, pode ser observado (figura 3 ) que, para os gestores de Desenvolvimento de Produto, este elemento possui apenas arcos de efeito sobre ele, sendo que outros quatro elementos 3 (capital humano), 7 (gestão do conhecimento), 12 (pesquisa e desenvolvimento) e 8 (imagem da marca) - pesam sobre o elemento 4.

Com um entendimento diferente, os gestores de Marketing apontam uma retroalimentação com outros oito elementos e um arco de efeito com o elemento 12 (pesquisa e desenvolvimento), como se vê na figura 4.

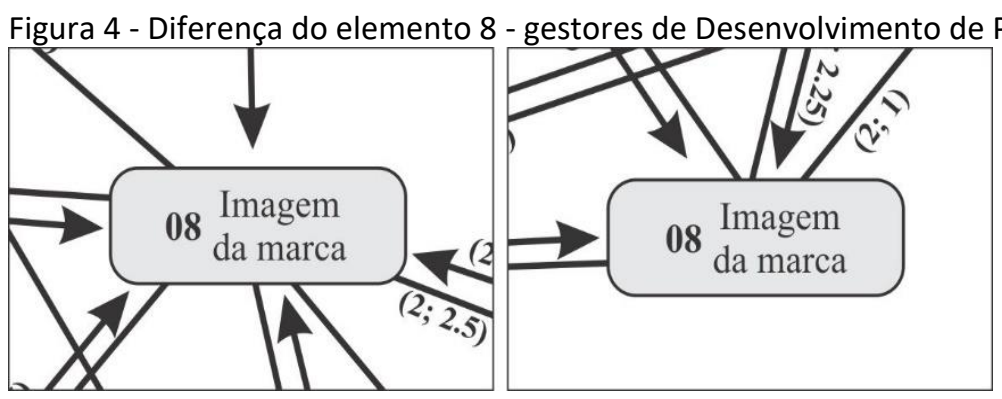

Fonte: Elaborada pelos autores (2018).

Com relação ao elemento 8 (imagem da marca), os gestores de Desenvolvimento de Produto afirmam que ele possui maior interação comparativamente ao entendimento dos gestores de Marketing, sendo 11 arcos de causa e efeito para os gestores de Desenvolvimento de Produto e somente sete arcos de causa e efeito para os gestores de Marketing. O elemento 8 (imagem da marca) é, no caso de ambos os gestores, apontado como importante.

Figura 5 - Diferença do elemento 12 - gestores de Desenvolvimento de Produto e gestores de Marketing

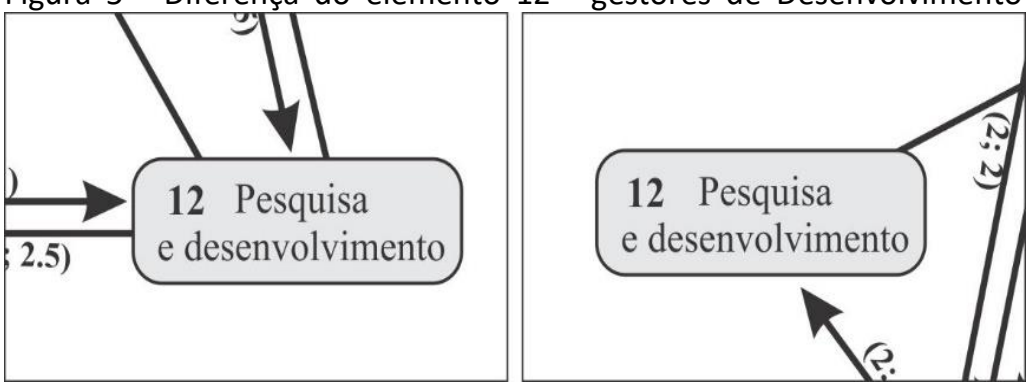

Fonte: Elaborada pelos autores (2018).

O elemento 12 (pesquisa e desenvolvimento) foi citado por ambos os grupos, porém, é apresentado de forma diferente por eles. Na figura 5, se observa que para os gestores de Desenvolvimento de Produto o elemento possui outros dois influenciadores, o 7 (gestão do conhecimento) e o 8 (imagem da marca), influenciando os elementos 4 (distribuição integrada), 7 (gestão do conhecimento) e 8 (imagem da marca). Por sua vez, o elemento 12 (pesquisa e desenvolvimento), para os gestores de Marketing, é influenciado apenas pelo elemento 14 [posicionamento (participação) no segmento de atuação] e influencia o elemento 4 (distribuição integrada). A partir destas constatações, se observa que o elemento 12 (pesquisa e desenvolvimento) implica maior preocupação e engajamento, segundo o entendimento dos gestores de Desenvolvimento de Produto. 
Figura 6 - Diferença do elemento 15 - gestores de Desenvolvimento de Produto e gestores de Marketing

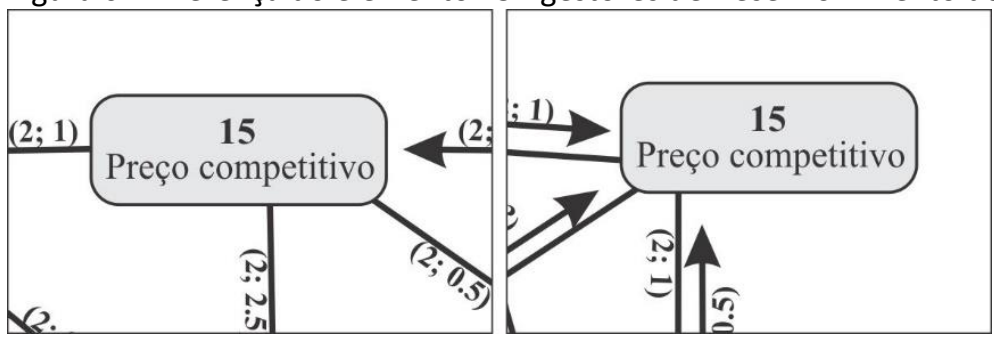

Fonte: Elaborada pelos autores (2018).

Conforme a figura 6, os gestores de Desenvolvimento de Produto entendem que o elemento 15 (preço competitivo) possui três arcos de causa sobre os elementos 04 (distribuição integrada), 8 (imagem da marca) e 20 (qualidade) e sofre influência do elemento 22 (responsabilidade social e ambiental). Para os gestores de Marketing, o elemento 15 (preço competitivo) sofre retroalimentação dos elementos 21 (relacionamento), 20 (qualidade) e 4 (distribuição integrada). Para este elemento, apesar de o número de arcos ser muito próximo, os gestores de Desenvolvimento de Produto entendem ser um forte influenciador, sofrendo menos interferência do que apontado pelos gestores de Marketing.

Figura 7 - Diferença do elemento 20 - gestores de Desenvolvimento de Produto e gestores de Marketing

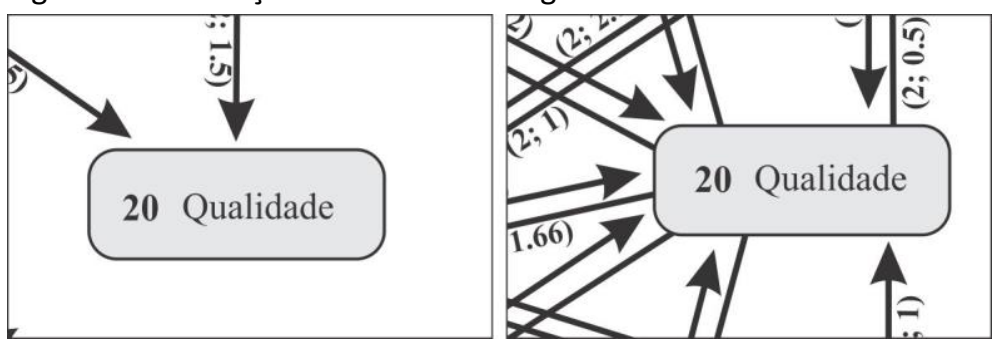

Fonte: Elaborada pelos autores (2018).

Conforme a figura 7, o elemento 20 (qualidade) possui diferença aparente entre os grupos de gestores. Para os de Desenvolvimento de Produto, a qualidade possui apenas dois arcos de efeito, sofrendo influência dos elementos 15 (preço competitivo) e 22 (respeito social e ambiental), e não influenciando nenhum outro elemento. Para os gestores de Marketing, o elemento 20 (qualidade), com 10 arcos de causa e efeito possui maior relevância, pois gera influência sobre os elementos 4 (distribuição integrada), 8 (imagem da marca), 14 [posicionamento (participação) no segmento de atuação], 15 (preço competitivo), 18 (benefícios do produto) e 21 (relacionamento) e sofre influência dos elementos 4 (distribuição integrada), 8 (imagem da marca), 14 [posicionamento (participação) no segmento de atuação], 15 (preço competitivo), 17 (atributos de produtos), 18 (benefícios do produto) e 21 (relacionamento). Este elemento mostra que para os gestores de Desenvolvimento de Produto a qualidade possui forte peso, porém, não exerce influência positiva nem negativa. Já para os gestores de Marketing, a qualidade é extremamente importante e esta pode ser entendida como forte influenciadora de diversos outros elementos de forma mais abrangente. 
Figura 8 - Diferença do elemento 21 - gestores de Desenvolvimento de Produto e gestores de Marketing

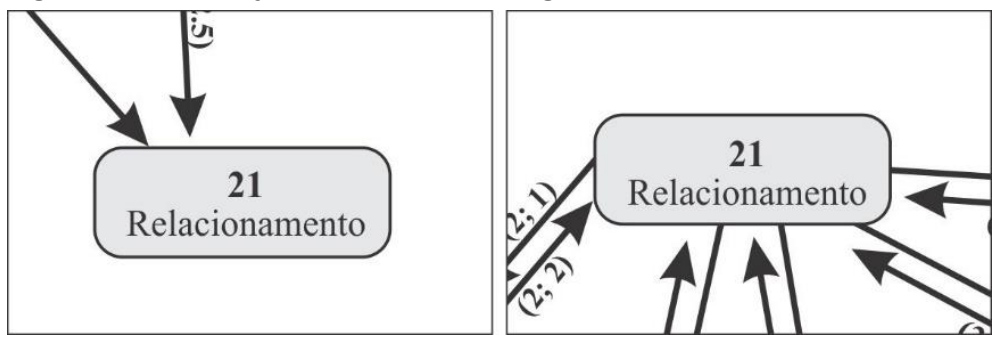

Fonte: Elaborada pelos autores (2018).

Como mostra a figura 8, para os gestores de Desenvolvimento de Produto o elemento 21 (relacionamento) possui apenas dois arcos de efeito e é influenciado pelos elementos 8 (imagem da marca) e 24 (tradição) - esta apontada apenas pelos gestores de Desenvolvimento de Produto. Já para os gestores de Marketing, o elemento 21 possui maior responsabilidade, apresentando arcos de causa e efeito com outros cinco elementos: 22 (respeito social e ambiental), 4 (distribuição integrada), 20 (qualidade), 15 (preço competitivo) e 14 (posicionamento) - este apontado somente pelos gestores de Marketing.

Figura 9 - Diferença do elemento 22 - gestores de Desenvolvimento de Produto e gestores de Marketing

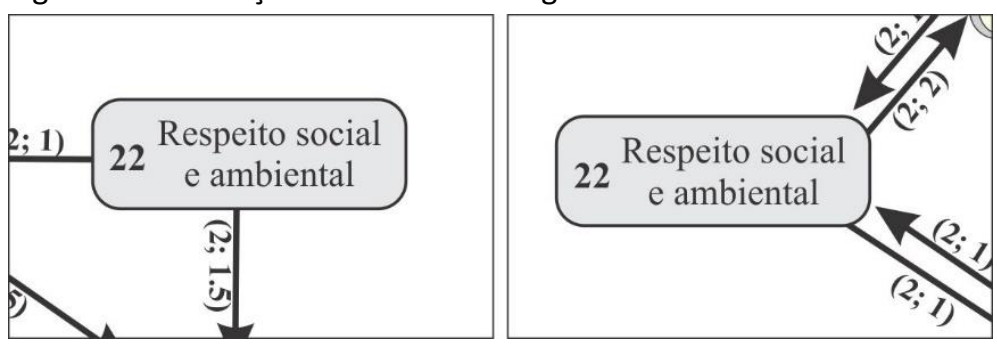

Fonte: Elaborada pelos autores (2018).

Quanto ao elemento 22 (respeito social e ambiental), ilustrado na figura 9, para os gestores de Desenvolvimento de Produto somente dois arcos de causa ocorrem, sobre os elementos 20 (qualidade) e 15 (preço competitivo). Para os gestores de Marketing, este elemento se retroalimenta em causa e efeito com os elementos 21 (relacionamento) e 4 (distribuição integrada). O elemento, apesar de ser citado por ambos os gestores, apresentou poucos arcos, o que demonstra baixo peso.

Ao se observar as diferenças, restou evidenciado o viés de entendimento dos gestores das duas diferentes áreas quanto aos elementos principais da proposta de valor de marca da sua empresa.

\section{DISCUSSÃO}

Após a análise dos dados, se procede discussão sobre os achados com o intuito de enriquecer o entendimento dos vários aspectos do estudo.

O quadro 1 , que trata da apresentação da proposta de valor das empresas participantes no entendimento dos gestores de Marketing e de Desenvolvimento de Produto, é suficientemente preciso na indicação de que há dessemelhança nesta compreensão. Independentemente da maneira com que os credos corporativos são comunicados internamente, iniciativas relacionadas ao mercado devem ser entendidas uniformemente pelos funcionários e demais colaboradores, pois são basilares para a sobrevivência empresarial. Para Tybout e Calkins (2006), os colaboradores são os principais grupos de 
interesse da marca e, sem apoio e comprometimento deles, a estratégia da marca provavelmente não será compreendida, gerando dificuldades em sua implementação. Frow et al. (2014) reforçam a argumentação da importância dos stakeholders internos, principalmente pela sua capacidade de aperfeiçoar ideias tendo por base os valores instilados pela organização.

Diversas são as motivações para que ocorram entendimentos diferentes sobre tão importante declaração empresarial, a proposta de valor. Segundo Jankovic (2012), comunicação inadequada, interesses voltados a poucos setores da empresa ou falta de visão no longo prazo podem estar entre essas motivações. No decorrer de um período, esse distanciamento entre o que é, de fato, a proposição de valor e aquilo que é compreendido como sendo ela, pode levar a dificuldades no processo de reconhecimento e de valorização da marca. Para Scharf (2012), esforços conjuntos para o desenvolvimento, a valorização e a manutenção de marcas fortes constituem o processo denominado de branding. A gestão de marcas pode ser prejudicada, caso não seja administrada adequadamente pelos decisores e demais stakeholders. Para So et al. (2013), o branding necessita de liderança forte e de diretrizes claras para que seja efetivo. Frow et al. (2014) argumentam que stakeholders mais bem preparados conseguem entregar mais qualidade às suas organizações por meio de serviços e ideias, gerando um ciclo positivo de valor à marca.

Apesar da diferença entre os entendimentos das duas áreas (Marketing e Desenvolvimento do Produto) para um mesmo conceito organizacional (proposta de valor), há aspectos convergentes. Os elementos que foram citados como importantes tanto por um quanto por outro profissional, tomando em conta a quantidade qualificada de conexões, calculada por meio da média das notas de influência segundo gradação estipulada de $-3 a+3$, são os relacionados com a imagem de marca e com o posicionamento no segmento de atuação. Ambos se referem diretamente aos aspectos decorrentes da maneira com que o consumidor avalia a marca, da forma com que ele interage com bens e serviços e da sua experiência com a marca adquirida.

Quanto a imagem, Aaker (2007) a considera um componente fundamental para a identidade da marca, um elemento essencial para a diferenciação no mercado. Os elementos constantes nas figuras 7 (qualidade), 8 (relacionamento) e 9 (responsabilidade social e ambiental) convergem para esse pensamento, e se suportam pelo conjunto de arcos e nós que apresentam, tanto por um quanto por outro profissional. Como se trata de um conjunto de empresas do setor de moda, essa realidade pode, ainda, ser majorada, dado o comportamento dos consumidores. Para Martin et al. (2007), consumidores de moda exigem algo como um crachá que possa ser usado tal qual uma declaração sobre a sua identidade. Os autores entendem que a imagem da marca deve ser relevante e atender às necessidades e aspirações desse indivíduo. Para Grönroos e Voima (2013), imagem de marca que contém valor prescinde de explicação, pois já é parte do cotidiano dos indivíduos.

Quanto ao posicionamento, Upshaw (1999) enfatiza que o conceito trata das características distintivas que tornam uma marca atraente e diferente da dos seus concorrentes. Amplia, dizendo que posicionamento envolve o convencimento dos consumidores sobre as vantagens do produto em relação às demais empresas ofertantes, permitindo um certo alívio quanto a possíveis desvantagens da compra. Os elementos constantes das figuras 5 (pesquisa e desenvolvimento) e 6 (preço competitivo) são mostras de que ambos os profissionais estão cônscios da sua responsabilidade na manutenção da proposta de valor, declaração fundamental para o adequado posicionamento da marca. Knox (2004) observa que o posicionamento é basilar para a eficiente gestão da marca, posto que o 
processo de branding assume aspectos tangíveis do produto e constrói os intangíveis na forma de uma imagem na mente das pessoas. Kohtamäki e Partanen (2016) entendem que elementos oriundos de áreas distintas podem contribuir para criar valor para a marca, tornando o posicionamento da empresa mais sólido no mercado.

É de se destacar, ainda, as pressões próprias da atividade de Marketing em organizações que atuam no ramo da moda. Às motivações já apontadas por Jankovic (2012) se soma uma certa desorganização típica de atividades que são muito volúveis. 0 redirecionamento constante na confecção dos produtos e nas atividades de divulgação pode dificultar ou mesmo minimizar a capacidade dos gestores de raciocinar a partir da proposta de valor. Sabidamente equivocada, essa situação pode ocorrer com constância, dada a cobrança por resultados no curto prazo que setores dessa natureza possuem. Martin et al. (2007) afirmam que as ações de Marketing para empresas de moda se destacam por serem diferentes de outras, principalmente pela rápida rotatividade do produto e as tendências de movimentação célere no varejo. Isto, segundo os autores, colocaria uma pressão diferente sobre as atividades de Marketing, e daria forte ênfase ao design, área que leva e reflete a demanda dos consumidores.

Não obstando as considerações presentes na literatura nem as observações realizadas na pesquisa de campo, é mister ter em conta que uma corporação deve zelar pela manutenção rigorosa da sua proposta de valor. Independentemente da condição do setor de atuação, se mais ou menos competitivo, se mais ou menos pulverizado, se mais ou menos instável, os colaboradores devem ter a proposição de valor como um credo a ser inserido nas atividades profissionais cotidianas. Walvis (2010) confirma o pensamento, ao dizer que coerência é um dos princípios do branding, devendo ser buscado o equilíbrio entre promessas, expectativas e entregas da organização, e que todos os pontos de contato devem apresentar mensagem coerente e única. Skålén, Gummerus, Von Koskull e Magnusson (2014), complementam ao dizer que estratégias competitivas devem trazer à empresa e sua marca, como resultado, mais valor. Para os autores, é internamente que se inicia a criação de valor que, posteriormente, será veiculada por todos os lados.

Ter presente, na mesma empresa, divergências no entendimento da proposta de valor por profissionais que possuem poder de mando em áreas significativas, é situação que gera óbices ao conjunto de iniciativas para geração de identidade, posicionamento e reconhecimento de marca. Portanto, ainda que seja de certa maneira compreensível e, mesmo, comum nas organizações, deve ser vista como um arranjo indesejado e esforços devem ser empreendidos no sentido de minimizar a ocorrência. Kapferer (2012) afirma que, sob pena de distorções na interpretação por parte do target, é necessário manter o significado da marca coeso entre todas as atividades empresariais.

\section{CONSIDERAÇÕES FINAIS}

O objetivo deste estudo foi identificar a proposta de valor de organizações detentoras de marcas de moda, na compreensão de decisores das áreas de Marketing e de Desenvolvimento de Produtos.

Como resultado principal, emergiu uma lacuna no alinhamento da proposta de valor da marca de moda internamente, entre os profissionais que tem à sua disposição poder de comando. Os gestores das duas áreas, pertencentes às mesmas empresas, apontaram elementos e relações diferentes, gerando falta de sincronicidade com as ações de branding dessas organizações. 
O fenômeno coloca em dúvida a efetiva compreensão de toda a equipe sobre o posicionamento da marca no mercado e sobre a imagem que os consumidores têm desta marca. Ao mesmo tempo, aponta deficiências no desenvolvimento da identidade da marca pela organização, impedindo a correta declaração exigida por uma proposta de valor.

Importante salientar que, apesar de os elementos não serem opostos neste estudo, também não são os mesmos. Consequentemente, os esforços desses profissionais, quanto ao estabelecimento de estratégias para o desenvolvimento da marca e a atuação operacional não são semelhantes, gerando possíveis problemas na continuidade dos aspectos de branding.

Ao investigar os elementos da proposta de valor por área de atuação, os gestores de Desenvolvimento de Produto atribuíram maior importância para o benefício do capital humano; já os gestores de Marketing destacaram elementos dos benefícios funcionais. A diferença apontada pode ser explicada pelo fato de os gestores de Desenvolvimento de Produto terem como natureza do seu trabalho a criatividade e a dedicação à pesquisa, características inerentes ao talento e à personalidade dos profissionais. Os gestores de Marketing que, por sua vez, possuem visão gerencial voltada ao mercado, demonstram ocupação com a declaração da proposta de valor a partir de elementos que apontem para os benefícios funcionais do produto, aqueles que permitem medir seu desempenho.

Este resultado, no entanto, deve ser observado à luz do que a organização tem como expectativa, basicamente que todos os seus profissionais compreendam de maneira semelhante a proposta de valor. Em não sendo assim, ou está errada a proposição ou estão equivocados os profissionais com poder de mando.

Ao final, algumas limitações precisam ser apontadas. Os elementos da proposta de valor são variáveis que, em outros trabalhos e por outros autores, podem ser apresentadas de forma diferente ou podem ter incluídos outros elementos e suas contribuições. Neste trabalho foram considerados somente os elementos da proposta de valor expostos por Scharf (2009; 2012), com a utilização da lista predefinida de elementos para que os decisores pudessem selecionar aqueles que acreditavam ser relevantes, o que foi suficiente para o objetivo desta pesquisa. Estudos podem buscar novos elementos para adoção de outra visão sobre a mesma temática. A segunda limitação diz respeito ao tipo de pesquisa e ao universo pesquisado. $O$ método utilizado possibilitou identificar apenas a forma como os especialistas do setor (gestores de Marketing e de Desenvolvimento de Produto) afirmam ser declarada a proposta de valor da marca de suas empresas, mas não permitiu avaliar se os consumidores de fato entendem da mesma maneira a proposta de valor veiculada pelas empresas participantes. Outra limitação é que mapas cognitivos não podem ser utilizados como método probabilístico, porque são o retrato de um momento do entendimento do entrevistado, como discutido nos trabalhos de Markóczy (1994). Para o autor, mapas cognitivos não podem ter a pretensão de ser uma representação perfeita da realidade, nem mesmo uma representação perfeita do modelo mental dos entrevistados. Por fim, como as estratégias de proposta de valor são incrementadas periodicamente, os dados que esta pesquisa encontrou e as diferenças nas opiniões dos gestores refletem um dado momento, não se podendo presumir que tal opinião continue a mesma ao longo do tempo. O acompanhamento da evolução das opiniões pode vir a ser objeto de nova investigação que dê continuidade a este trabalho.

São recomendadas, portanto, algumas proposições de estudos futuros. Uma delas se refere a uma investigação longitudinal, com mapas em determinado momento e outros após novo alinhamento com todos os envolvidos, gerando, assim, confirmação do entendimento destes quanto às estratégias de proposição de valor. Outra proposta trata de um estudo que 
envolva o consumidor, identificando e comparando a proposição de valor da empresa nas duas percepções, a do comprador e a do fabricante de moda. Por último, se sugere que estudos dessa natureza possam abarcar outros fabricantes de moda, além do estudado (vestuário), tais como indústrias de relógios, perfumes, sapatos e outras ramificações que configuram o setor de moda.

\section{REFERÊNCIAS}

AAKER, D. A. Construindo marcas fortes. Porto Alegre: Bookman, 2007.

AAKER, D. A; JOACHIMSTHALER, E. The brand relationship spectrum: the key to the brand architecture challenge. California Management Review, v. 42, n. 4, p. 8-23, 2000.

ALVEREZ, F. J. S. M.; FAVERO, M. B.; FRANCISCO, G. D. Marcas de moda e a percepção dos consumidores. Projética, v. 4, p. 65-82, 2013.

BARRETO, I. F. Resultados de Marketing de relacionamento: proposição de modelo por meio de mapeamento cognitivo. Tese (Doutorado em Administração) - Universidade de São Paulo, São Paulo, 2015.

BASTOS, A. V. B. Mapas cognitivos e a pesquisa organizacional: explorando aspectos metodológicos. Estudos de Psicologia, v. 7, n. especial, p. 65-77, 2002.

BIRTWISTLE, G.; FREATHY, P. More than just a name above the shop: a comparison of the branding strategies of two UK fashion retailers. International Journal of Retail \& Distribution Management, v. 26, n. 8, p. 318-323, 1998.

BITITCI, U. S.; MARTINEZ, V.; ALBORES, P.; PARUNG, J. Creating and managing value in collaborative networks. International Journal of Physical Distribution \& Logistics Management, v. 34, n. 3, p. 251-268, 2004.

BRANDINI, V. Vestindo a rua: moda, comunicação \& metrópole. Fronteiras - estudos midiáticos, v. 4, n. 1, p. 23-33, 2007.

BRIIDSSON, K.; EVANS, J. The secret to fashion advantage is brand orientation. International Journal of Retail \& Distribution Management, v. 32, n. 8, p. 403-411, 2004.

CHRISTOPHER, M.; LOWSON, R.; PECK, H. Creating agile supply chains in the fashion industry. International Journal of Retail and Distribution Management, v. 32, n. 8, p. 367-376, 2004.

CRESCITELLI, E.; FIGUEIREDO, J. Uso de diagramas causais na construção de um modelo de brand equity. Florianópolis: EMA, 2010.

DAVIS, S. M. Brand asset management: driving profitable growth through yours brands. São Francisco: Jossey-bass, 2000.

EDEN, C. Cognitive mapping. European Journal of Operational Research, v.36, n. 1, p. 1-13, 1988.

EDEN, C. Using cognitive mapping for strategic options development and analysis (SODA). In ROSENHEAD, J. (ed.). Rational analysis for a problematic world: problem struturing methods for complexity, uncertanly and conflict. London: Willey, 1989. 370p.

FIESC Federação das Indústrias do Estado de Santa Catarina. Disponível em https://www.fiesc.com.br/. Acesso em: 4 mar. 2018. 
FROW, P.; McCOLL-KENNEDY, J. R.; HILTON, T.; DAVIDSON, A.; PAYNE, A.; BROZOVIC, D. Value propositions: A service ecosystems perspective. Marketing Theory, v. 14, n. 3, p. 327351, 2014.

FROW, P. PAYNE, A. A stakeholder perspective of the value proposition concept. European Journal of Marketing, v. 45, n 1/2, p. 223-240, 2011.

GARCÍA, M. M. Arquitectura de marcas: modelo general de construcción de marcas y gestión de sus activos. Madrid: ESIC Editorial, 2005.

GHODESWAR, B. M. Building brand identity in competitive markets: a conceptual model. Journal of Product \& Brand Management, v. 17, n. 1, p. 4-12, 2008.

GRÖNROOS, C.; VOIMA, P. Critical service logic: making sence of value creation and cocreation. Journal of the Academy of Marketing Science, v. 41, n. 2, p. 133-150, 2013.

HALL, S. A identidade cultural na pós-modernidade. Rio de Janeiro: DP\&A, 2006.

JANKOVIC, M. Integrated Marketing communications and brand identity development management. Journal for Theory and Practice of Management, v. 17, n. 63, p. 91-97, 2012.

KAPFERER, J-N. As marcas: capital da empresa: criar e desenvolver marcas fortes. Porto Alegre: Bookman, 2003.

KAPFERER, J-N. The new strategic brand management: Advanced insights \& strategic thinking. London: Kogan Page, 2012.

KARJALAINEN, T-M. It looks like a Toyota: educational approaches to designing for visual brand recognition. International Journal of Design, v. 1, n. 1, p. 67-81, 2007.

KELLER, K. L.; MACHADO, M. Gestão estratégica de marcas. São Paulo: Pearson Prentice Hall, 2006.

KNOX, C. Positioning and branding your organization. Journal of Product and Brand Management, v. 13, n. 3, p. 105-115, 2004.

KOHTAMÄKI, M.; PARTANEN, J. Co-creating value from knowledge-intensive business services in manufacturing firms: the moderating role of relationship learning in suppliercustomer interactions. Journal for Business Research, v. 69, n. 7, p. 2498-2506, 2016.

KOWALKOWSKI, C. Dynamics of value propositions: insights from service-dominant logic. European Journal of Marketing, v. 45, n. 1/2, p. 277-294, 2011.

LEWIS, B. R. B.; HAWKSLEY, A. A. W. Gaining a competitive advantage in fashion retailing. International Journal of Retail, v. 18, n. 4, p. 59-73, 1990.

LIPOVETSKY, G. O império do efêmero: a moda e seu destino nas sociedades modernas. São Paulo, SP: Editora Schwarcz, 2002.

MANDHACHITARA, R.; PIAMPHONGSANT, T. Professional women's fashionable clothing decisions in Bangkok and New York City. Journal of International Consumer Marketing, v. 1530. p. 1-15, 2016.

MARKÓCZY, L. A. Barriers to shared belief: the role of strategic interest, managerial characteristics and organisational factors. (Doctoral dissertation) - The University of Cambridge, Cambridge, United Kigdom, 1994. 
MARTIN, B.; VEER, E.; PERVAN, S. Self-referencing and consumer evaluations of larger-sized female models: A weight locus of control perspective. Marketing Letters, v.18, n. 3, p. 197209, 2007.

MCCRACKEN, G. Cultura \& Consumo II: mercados, significados e gerenciamento de marcas. Rio de Janeiro: Mauad, 2012.

MINDRUT, S.; MANOLICA, A.; ROMAN, C. T. Building brands identity. Procedia Economics and Finance, v. 20, p. 393-403, 2015.

NUNES, G. Marca: valor do intangível. São Paulo: Atlas, 2003.

O'HARA, G. Enciclopédia da moda: de 1840 à década de 80. São Paulo: Companhia das Letras, 1993.

RECH, S. R. Cadeia produtiva da moda: um modelo conceitual de análise da competitividade no elo confecção. Florianópolis: UFSC, 2006.

SCHARF, E. R. Proposta de valor na construção de identidade de marca: o capital humano evoluindo na área mercadológica. Tese (Doutorado em Engenharia e Gestão do Conhecimento) - Universidade Federal de Santa Catarina, Florianópolis. 2009.

SCHARF, E. R. A proposta de valor e o capital humano: práticas estratégicas de Marketing. Revista Brasileira de Gestão de Negócios, v. 14, n. 43, p. 216-233, 2012.

SCHARF, E. R.; VIEIRA, F. G. D.; KRAUSE, R. Estudos sobre identidade de marca: uma análise sobre a produção acadêmica brasileira de 1997 a 2011. Revista Eletrônica de Gestão Organizacional, v. 11, n. 1, p. 34-61, 2013.

SCMC Santa Catarina Moda \& Cultura. Disponível em https://www.scmc.com.br/. Acessado em 2 fev. 2018.

SILVA, E. L.; MENEZES, E. M. Metodologia da pesquisa e elaboração de dissertação. 4. ed. Florianópolis: UFSC, 2005.

SKÅLÉN, P.; GUMMERUS, J.; Von KOSKULL, C.; MAGNUSSON, P. Exploring value propositions and service innovation: A service-dominant logic study. Journal of the Academy of Marketing Science, v. 42, n. 2, p. 137-158, 2014.

SO, J. T.; PARSONS, A. G.; YAP, S. Corporate branding, emotional attachment and brand loyalty: the case of luxury fashion branding. Journal of Fashion Marketing and Management, v. 17, n. 4, p. 403-423, 2013.

SOUZA, G. de M. O espírito das roupas: a moda no século dezenove. São Paulo: Companhia das Letras, 1996.

TREACY, M.; WIERSEMA, F. The disciplines of the Market leaders. London: HarperCollins, 1996.

TUOMINEN, M. Channel collaboration and firm value proposition. International Journal of Retail \& Distribution Management, v. 32, n. 4, p. 178-189, 2004.

TYBOUT, A. M; CALKINS, T. (org.) Branding. São Paulo: Atlas, 2006.

UPSHAW, L. B. Building brand identity: A strategy for success in a hostile marketplace. New York: John Wiley \& Sons, 1999. 
VARADARAJAN, R. Marketing strategy: discerning the relative influence of product and firm characteristics. AMS Review, v. 1, n. 1, p. 32-43, 2011.

VERGARA, S. C. Projetos e relatórios de pesquisa em administração. 3. ed. São Paulo: Atlas, 2000.

WALVIS, T. Branding with brains. Londres: Pearson Education, 2010. 